\title{
AC 2011-1506: INTEGRATING LECTURE AND LABORATORY IN AN ANALOG ELECTRONICS COURSE USING AN ELECTRONICS EXPLORER BOARD
}

\section{Kenneth V Noren, University of Idaho, Moscow}

Kenneth V. Noren recieved the B.S., M.S. and Ph.D. degrees in electrical engineering from Michigan State University in East Lansing, Michigan, in 1987, 1989, and 1992, respectively. He is a Associate Professor in the Department of Electrical Engineering at the University of Idaho located in Moscow, Idaho. His research interests are in the area of design and modeling of analog and mixed-signal integrated circuits and in methods for engineering education. 


\section{Integrating Lecture and Laboratory in an Analog Electronics Course Using an Electronics Explorer Board}

\section{Introduction}

It is well documented that when students have a hands-on experience with the concepts taught in the electrical engineering classroom, a deeper understanding of the concepts can be obtained [15]. Today's students need more hands-on experience to reinforce basic concepts than students of yesterday [6,7]. Even so, experienced students still benefit from hands-on [8]. Students usually get laboratory work to go along with their classes at the sophomore and junior level, but not so much at the senior level.

Providing a hands-on experience to reinforce concepts in classes from freshmen to senior is difficult due to resource limitations. Moreover, universities that strive to offer an outreach program have a more difficult problem providing students with a laboratory experience. For example, University of North Dakota offers an undergraduate degree through outreach. The students have to come to campus for an intensive, one-week session when the laboratories are performed.

Past efforts to successfully offer laboratory experiments as part of senior level courses in analog electronics at the University of Idaho were largely unsuccessful for another reason, inconvenience felt by the students. They had to be on-campus during specific times to use the laboratory facilities of the department.

In the Fall Semester of 2010, a laboratory component was added to a senior-level course entitled "Applications of Linear IC's". This course is an analog electronics course that teaches operational amplifiers, comparators, voltage regulators and references, and applications that use these components. A laboratory dimension was added to the course using an "Electronics Explorer Board" manufactured by Digilent. Additional equipment included a very inexpensive digital multimeter (DMM) that measured resistance, capacitance, and AC voltages. Along with a personal computer, this provided students with their own "circuits and electronics" laboratory. The classroom lectures explain the concepts included in the experiments was well as an analysis of the circuits used in the experiments. The experiments are assigned as part of the homework problems. The laboratory is in effect, integrated into the class and lectures. The lecture material did not change from the previous time the class was offered. Only a laboratory component was added to the class to reinforce the topics discussed in the lectures. This was used as a test to see if the approach could be used in other senior level courses.

In the Spring Semester of 2011 it will be tested in a junior-level electronics course and future plans are to test it in a freshman -level course. The overall aim is to see if a curriculum-wide adoption of the board will be beneficial to the students.

There is a project similar to the Digilent board known as "Lab-in-a-Box" at developed at Virginia Tech and being used by Virginia Tech several community colleges in Virginia [9]. It is not known whether or not this available for use at other universities. 


\section{The Digilent Electronics Explorer Board}

A picture of the Digilent Electronics Explorer Board is shown in Figure 1. The board features a 4-channel, 40MSa oscilloscope, a 4-channel DC voltmeter, two programmable reference voltages, two arbitrary waveform generators, and a triple-output power supply, two of the power



Figure 1: A picture of the Digilent Electronics Explorer Board

supplies being programmable. There are also digital features. These include a 32-channel logic analyzer, a 32-channel pattern generator, and digital I/Os including button, switches, and LEDs, to name a few. Only the analog features were used in the course.

All instrumentation is controlled by computer through a USB port and software available from Digilent. Power is applied to the board through a $12 \mathrm{~V}$ DC power supply connected to $120 \mathrm{~Hz}$.

In addition to being able to display four channels, the oscilloscope allows for mathematical functions to be displayed, such as "Channel 1 minus Channel 2" for example. There is an XY feature that is very useful for generating IV curves for two and three terminal devices. The spectrum of the signals of the oscilloscope can also be displayed. The oscilloscope can also take measurements of the displayed waveforms. These measurements include the maximum, minimum, average, peak-to-peak, amplitude, DC and AC rms values of the displayed waveforms. Frequency, duty cycle, positive and negative width can also be displayed.

The waveform generator is quite powerful. In addition to being able to generate sine, square, and triangle waves, the user can generate custom waveforms. The numbers of possible waveforms are endless. 
The main differences between the Lab-in-a-Box (the only alternative known) and the Electronics Explorer board can be seen in the DC power supplies, the waveform generator, and the oscilloscope features [9].

There are three fixed power supplies on the "Lab-in-a-Box" of $5 \mathrm{~V}$ and $\pm 9 \mathrm{~V}$. The Electronics Explorer board has two programmable DC power supplies and one that can be operated at . Two can be programmable between $\pm 9 \mathrm{~V}$ and the third can be programmed at. There are also two voltage references on board the Electronics Explorer board that can be programmed between \pm $10 \mathrm{~V}$

The function generator on board the "Lab-in-a-Box" can generator a single adjustable sine or square wave. There are two waveform generators on board the Digilent board. As mentioned earlier, they can generate sine, square, and triangle waves, and also the user defined custom waveforms.

There is no oscilloscope with the "Lab-in-a-Box". It is recommended that the board be used with a software oscilloscope.

\section{Laboratory Experiments}

Students check out an electronics board, a DMM, and parts. Most of the students performed the experiments at their residence, but some chose to work in small groups in a department laboratory that had computers in which the software required to operate the board was installed. It was required that two of the laboratories be demonstrated to the instructor. For these, the students brought the electronics boards to the instructors' office where designed circuits could be demonstrated in less than one minute. The requirements for documentation were lean. Mainly, imported measurements and waveforms into a document and a discussion of the differences between what was predicted and what was measured.

The experiments were designed with the following objectives in mind:

(1) The experiments should be able to able to be performed in about one hour. This includes documentation. When necessary, as was often the case early in the semester, troubleshooting added more time. One of the experiments was conducted over two weeks. The time constraint was imposed because the laboratory portion of the course was given as part of the course homework assignments.

(2) A mixture of simple, basic, experiments used to illustrate fundament concepts and experiments that were easy circuit designs. Design assignments used the design, simulate, build, test and evaluate procedure.

A short description of the laboratory experiments follows. For the experiments titled "Wien Bridge Oscillator" and "Overcoming Op-amp Limitations," sample output is presented. 
(1) Introduction to the Digilent Electronics Explorer Board

This exercise was written to give the students a basic introduction to the features of the board and to lay the framework for how to export measurements, waveform displays, and data for the purposes of reporting.

(2) Inverting Amplifier

This exercise provided a gentle introduction to building and testing a circuit using the board by building and testing an inverting amplifier.

(3) Instrumentation System to Measure Cantilever Deflection

This was a two-week design, simulate, build, test and evaluate experiment. A schematic of the system is shown in Figure 2. The goal was to design the system so that $\mathrm{v}_{\mathrm{O}}=5 \mathrm{~V}$ when a cantilever was up and $\mathrm{v}_{\mathrm{O}}=-5 \mathrm{~V}$ when the cantilever was down.

It consisted of a strain gage attached to a cantilever, a bridge circuit that required calibrating, and a traditional three op-amp instrumentation system that required calibration. Referring to Figure 2, the strain gage is modeled with $R_{\text {strain. }}$ A $5 \mathrm{k} \Omega$ potentiometer was used for $\mathrm{R}_{\mathrm{adj}}$ and was adjusted to tune $\mathrm{V}_{\text {bridge }}$ to zero for the case where the cantilever was unstressed. $\mathrm{R}_{\mathrm{G}}$ is also a $5 \mathrm{k} \Omega$ potentiometer and was used to adjust the gain of the three opamp instrumentation amplifier to achieve $\pm 5 \mathrm{~V}$ (approximately) when the cantilever was fully up or down.

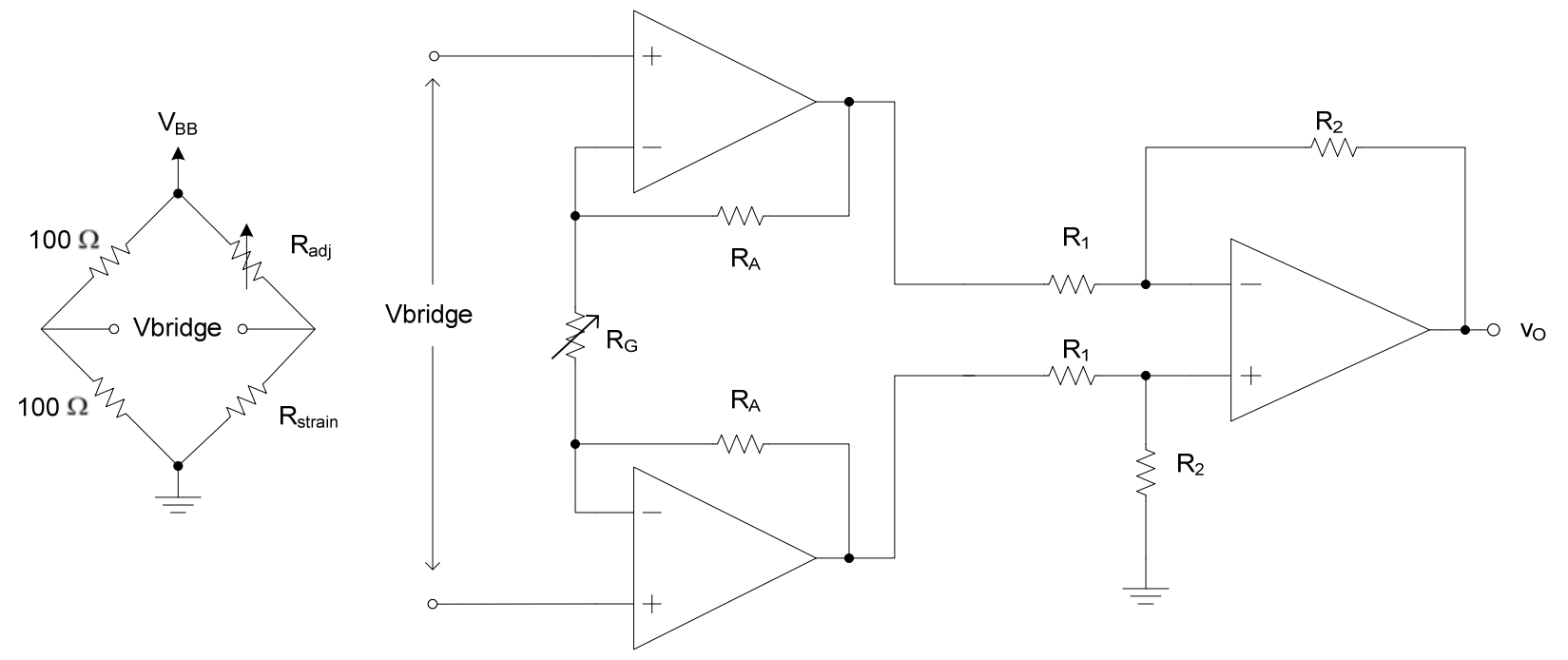

Figure 2: An instrumentation system to measure deflection of a cantilever.

(4) Second Order Active Bandpass Filter

This was a design, simulate, build, test and evaluate experiment. The schematic for the circuit is depicted in Figure 3. It is the well known Infinite Gain, Multiple Feedback 
topology. The students designed the filter to meet at set of target specifications for the center frequency, the gain at center frequency, and the bandwidth. These parameters were measured and the values compared to hand calculations and simulations.

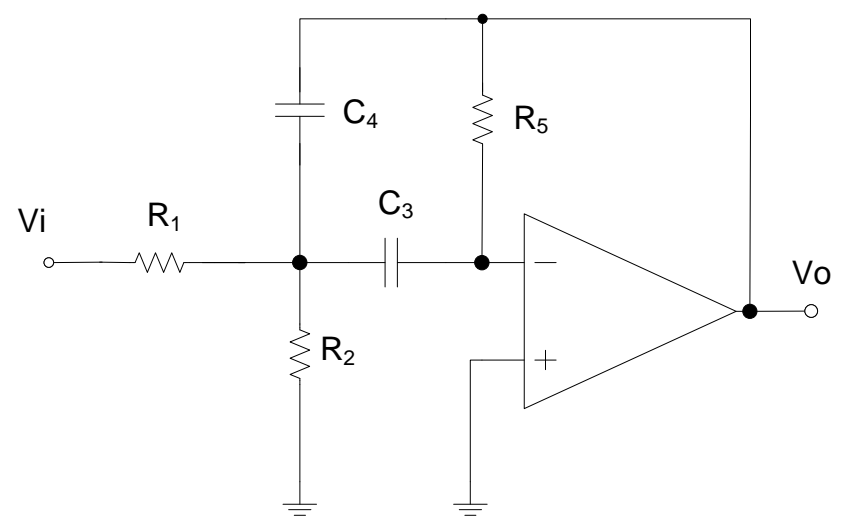

Figure 3: A $2^{\text {nd }}$ order bandpass circuit using the Infinite Gain, Multiple Feedback topology.

\section{(5) Non-Ideal Op-Amp Effects}

Students measured the upper and lower saturation voltages, maximum source and sink current, and slew rate of a 741 op-amp. A unity gain buffer with a square wave input of $5 \mathrm{~V}$ peak is used to measure the slew rate. A plot of the input and output of the unity gain follower is depicted in Figure 5. $\mathrm{C} 1$ is the input to the unity gain follower and C2 is the output. Slew rate for both a decrease and increase in output voltages are determined by measuring the positive and negative voltage slopes of the output voltage.

To discuss overcoming the current limitation of an of-amp, a push-pull amplifier is built and DC transfer curves are generated. The push-pull amplifier consists of the two transistors and two 68 $\Omega$ emitter resistors depicted in inverting amplifier Figure 5. The DC transfer curve for the pushpull amplifier is depicted in Figure 6.

An inverting amplifier with a gain of $10 \mathrm{~V} / \mathrm{V}$ driving a $47 \Omega$ load is built and tested to demonstrate the current limitations of the op-amp. The current limitation is detectable by observing that the output waveform is clipped. A push-pull amplifier is added inside the feedback loop, demonstrating a method for overcoming the current limitation. Figure 7 shows the input and output voltages for the circuit of Figure 5. A small amount of cross over distortion is noted. 


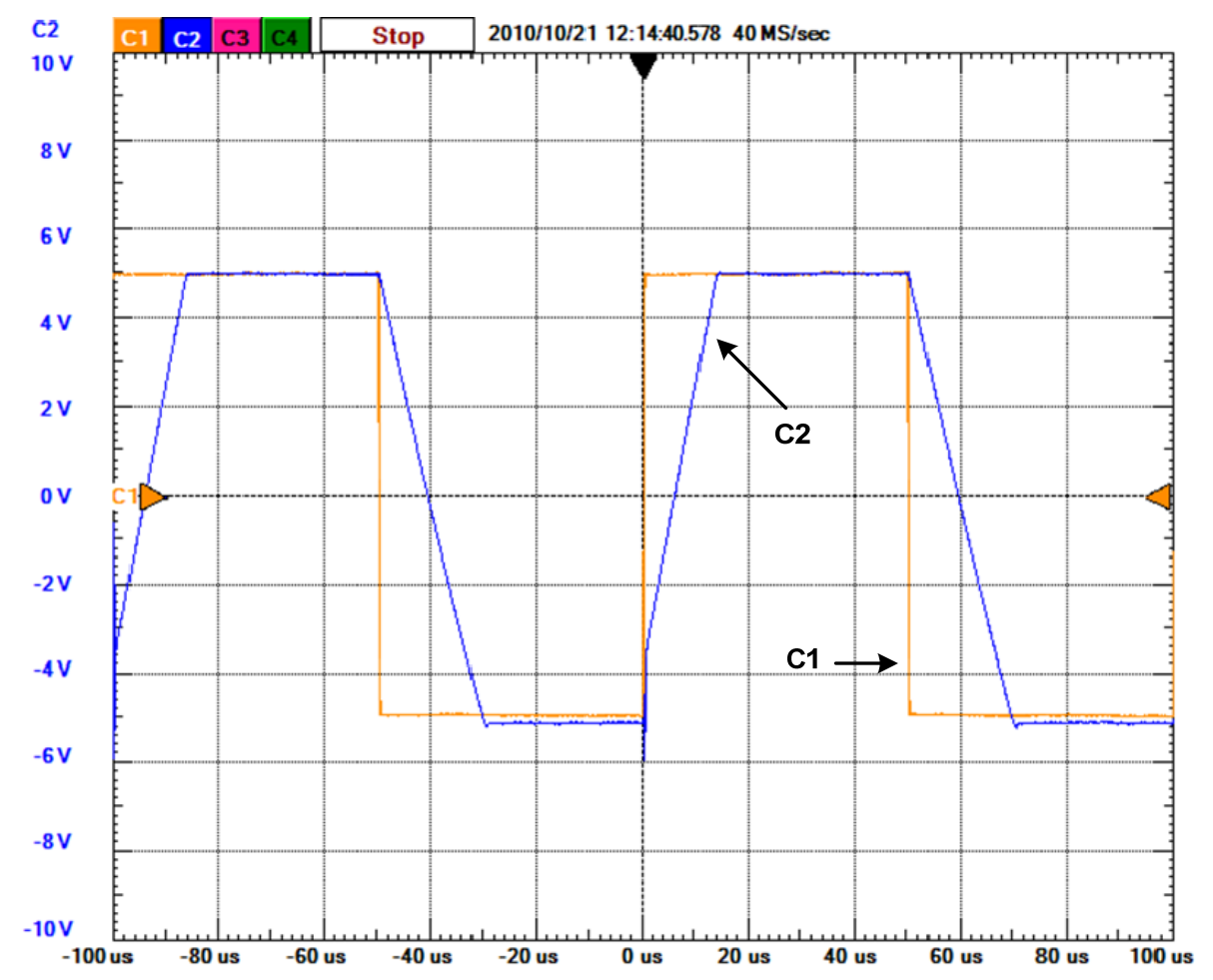

Figure 4: The input and output of a unity gain follower used to measure slew rate. $\mathrm{C} 1$ is the input to the unity gain follower and $\mathrm{C} 2$ is the output.



Figure 5: An inverting amplifier employing a push-pull circuit to drive $47 \Omega$ load. 


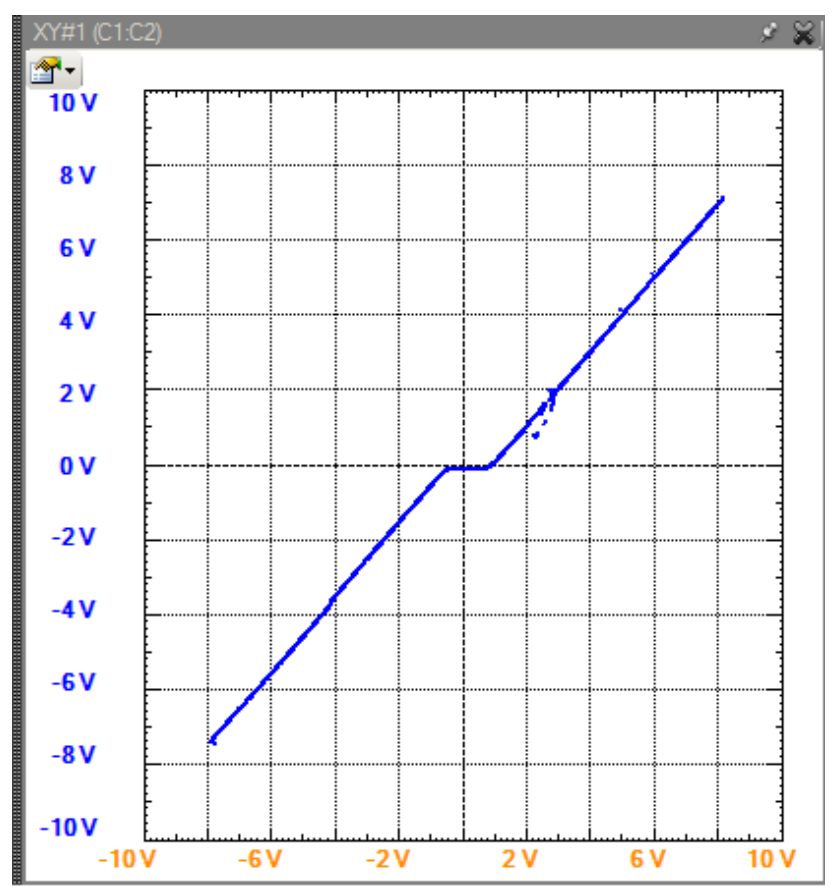

Figure 6: The DC transfer curves for a push-pull amplifier.

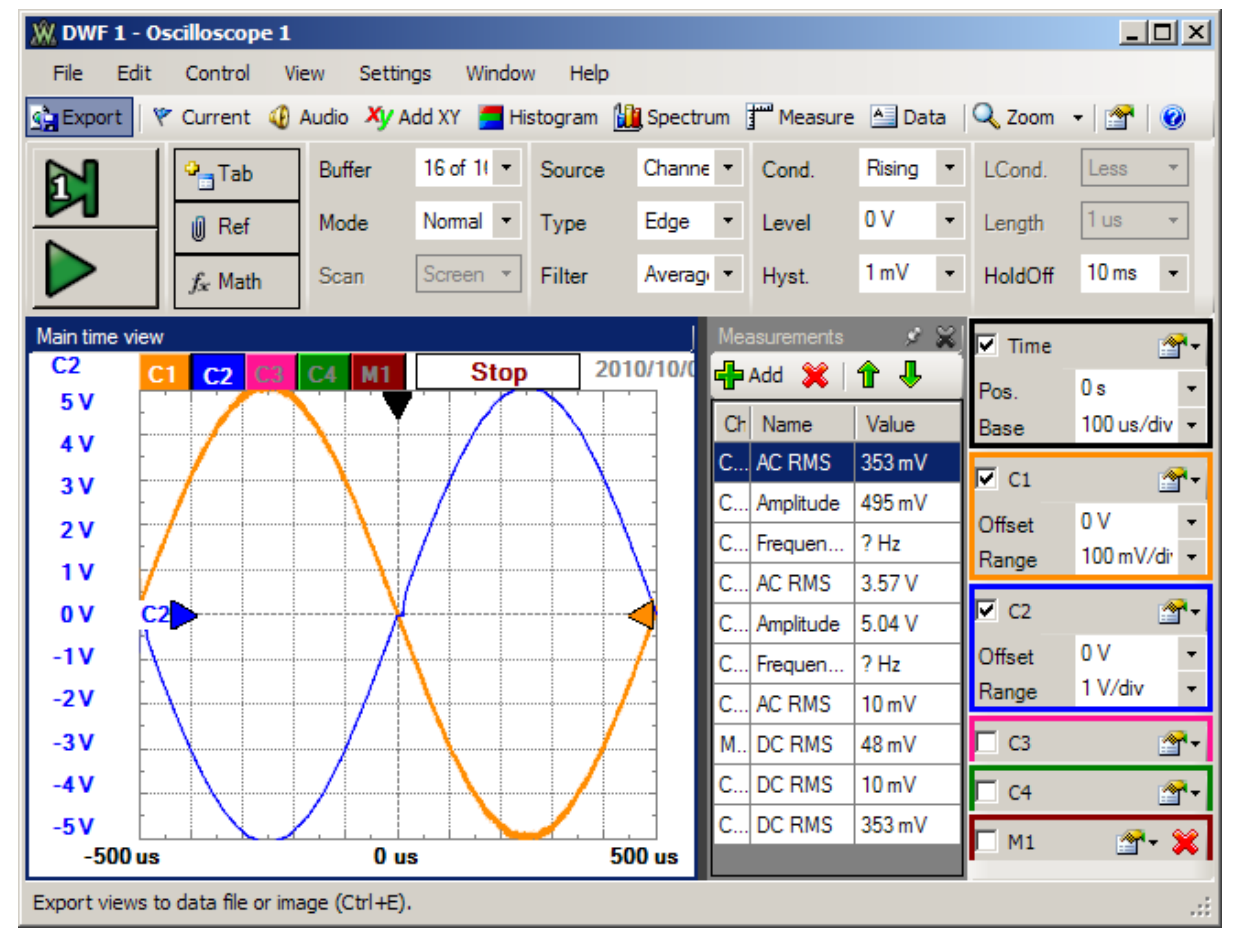

Figure 7: The input and output of a inverting amplifier with a push-pull circuit. The output waveform shows crossover distortion. 
(6) Inverting Amplifier in Single-Supply Operation

Students demonstrated that a 741 op-amp can be used in single-supply applications. The inverting amplifier demonstrated the need to consider DC biasing of the op-amp and capacitive coupling of the input and output to the amplifier. The circuit is depicted in Figure 8. The two $47 \mu \mathrm{F}$ capacitors are coupling capacitors. For DC, they are treated as open. The voltage at the positive terminal is biased at $\mathrm{V}_{\mathrm{CC}} / 2$ or $4.5 \mathrm{~V}$ by the voltage divided formed by $\mathrm{R}_{\mathrm{B} 1}$ and $\mathrm{R}_{\mathrm{B} 2}$. Since the $\mathrm{DC}$ circuit has feedback, the voltage at the negative terminal is also at $4.5 \mathrm{~V}$. Since no DC current flows through R2, there is no voltage drop across it and $\mathrm{v}_{\mathrm{OA}}=4.5 \mathrm{~V}$. Thus, the input and output terminals of the opamp are biased at $\mathrm{V}_{\mathrm{CC}} / 2$.

For AC operation, the circuit functions as an inverting amplifier with a gain of $\mathrm{R}_{2} / \mathrm{R}_{1}=10$ $\mathrm{V} / \mathrm{V}$. The voltage at $\mathrm{V}_{\mathrm{OA}}$ consists of $4.5 \mathrm{~V}$ DC plus the signal due to $\mathrm{v}_{\mathrm{I}}$. The $47 \mu \mathrm{F}$ capacitor at the output filters the DC component of $\mathrm{v}_{\mathrm{OA}}$, leaving only the signal component due to $v_{I}$ at $v_{O}$. For this circuit, $v_{O} / v_{I}=-R_{2} / R_{1}$

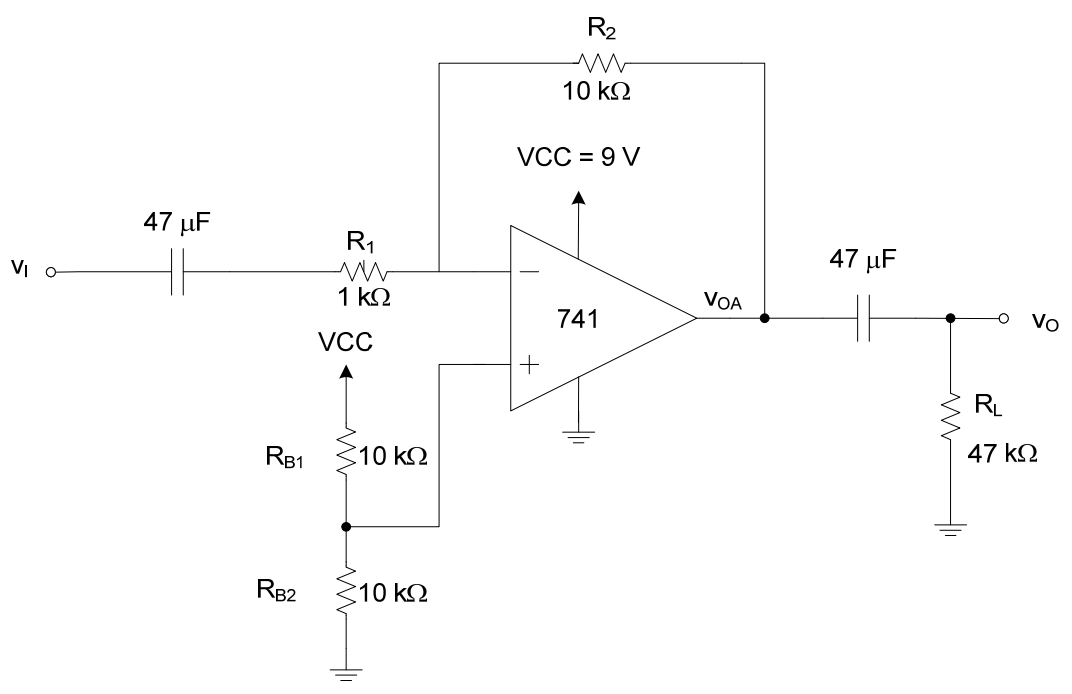

Figure 8: An inverting amplifier operating in single-supply mode.

(7) Wein Bridge Oscillator

A Wein Bridge Oscillator is built to demonstrate feedback concepts and voltage stabilization of oscillators using non-linear devices (diodes in this case). The schematic of the Wein Bridge oscillator is shown in Figure 9.

Figure 10 shows the output of the Wein Bridge Oscillator and Figure 11 shows measurements taken by an oscilloscope function. The frequency, maximum and minimum values are measured.

Figure 11 shows the spectrum of the output of the Wien bridge oscillator using the spectrum analyzer feature of the oscilloscope. The table shows the values of the harmonics. 


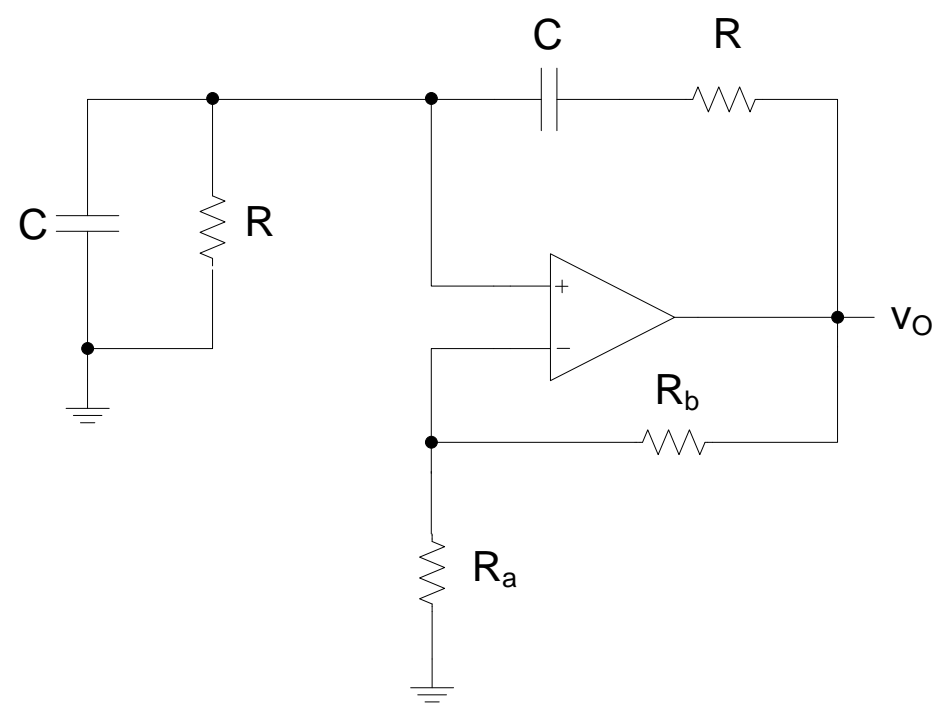

Figure 9: A Wein Bridge oscillator with voltage limiting circuitry



Figure 10: The output waveform of Wien Bridge oscillator. 


Measurements
\begin{tabular}{|l|l|l|}
\hline ß3Add $\& \mid$ U \\
\hline Ch & Name & Value \\
\hline C1 & Maximum & $8.08 \mathrm{~V}$ \\
\hline C1 & Minimum & $-6.86 \mathrm{~V}$ \\
\hline C1 & Frequency & $971 \mathrm{~Hz}$ \\
\hline
\end{tabular}

Figure 11: Measurements for the Wien Bridge oscillator. The measurements include maximum and minimum voltages and frequency of oscillation.

\begin{tabular}{|c|c|c|c|}
\hline \multicolumn{2}{|c|}{ Components of C1 I } & \multicolumn{2}{|c|}{$\mathrm{C} 2 \mathrm{C} 3$} \\
\hline Idx & Frequency & Amplitude & $\Delta$ \\
\hline 1 & $955 \mathrm{~Hz}$ & $7.685 \mathrm{~V}$ & \\
\hline 2 & $1.915 \mathrm{kHz}$ & $370 \mathrm{mV}$ & \\
\hline 3 & $\mathrm{OHz}$ & $305 \mathrm{mV}$ & \\
\hline 4 & $2.88 \mathrm{kHz}$ & $175 \mathrm{mV}$ & \\
\hline 5 & $3.84 \mathrm{kHz}$ & $140 \mathrm{mV}$ & \\
\hline 6 & $4.795 \mathrm{kHz}$ & $100 \mathrm{mV}$ & \\
\hline 7 & $5.75 \mathrm{kHz}$ & $65 \mathrm{mV}$ & \\
\hline 8 & $780 \mathrm{~Hz}$ & $65 \mathrm{mV}$ & \\
\hline 9 & $740 \mathrm{~Hz}$ & $60 \mathrm{mV}$ & \\
\hline 10 & $820 \mathrm{~Hz}$ & $55 \mathrm{mV}$ & \\
\hline 11 & $705 \mathrm{~Hz}$ & $55 \mathrm{mV}$ & \\
\hline 12 & $665 \mathrm{~Hz}$ & $50 \mathrm{mV}$ & \\
\hline 13 & $1.145 \mathrm{kHz}$ & $50 \mathrm{mV}$ & \\
\hline 14 & $1.18 \mathrm{kHz}$ & $45 \mathrm{mV}$ & \\
\hline 15 & $615 \mathrm{~Hz}$ & $45 \mathrm{mV}$ & \\
\hline 16 & $575 \mathrm{~Hz}$ & $45 \mathrm{mV}$ & $\nabla$ \\
\hline
\end{tabular}

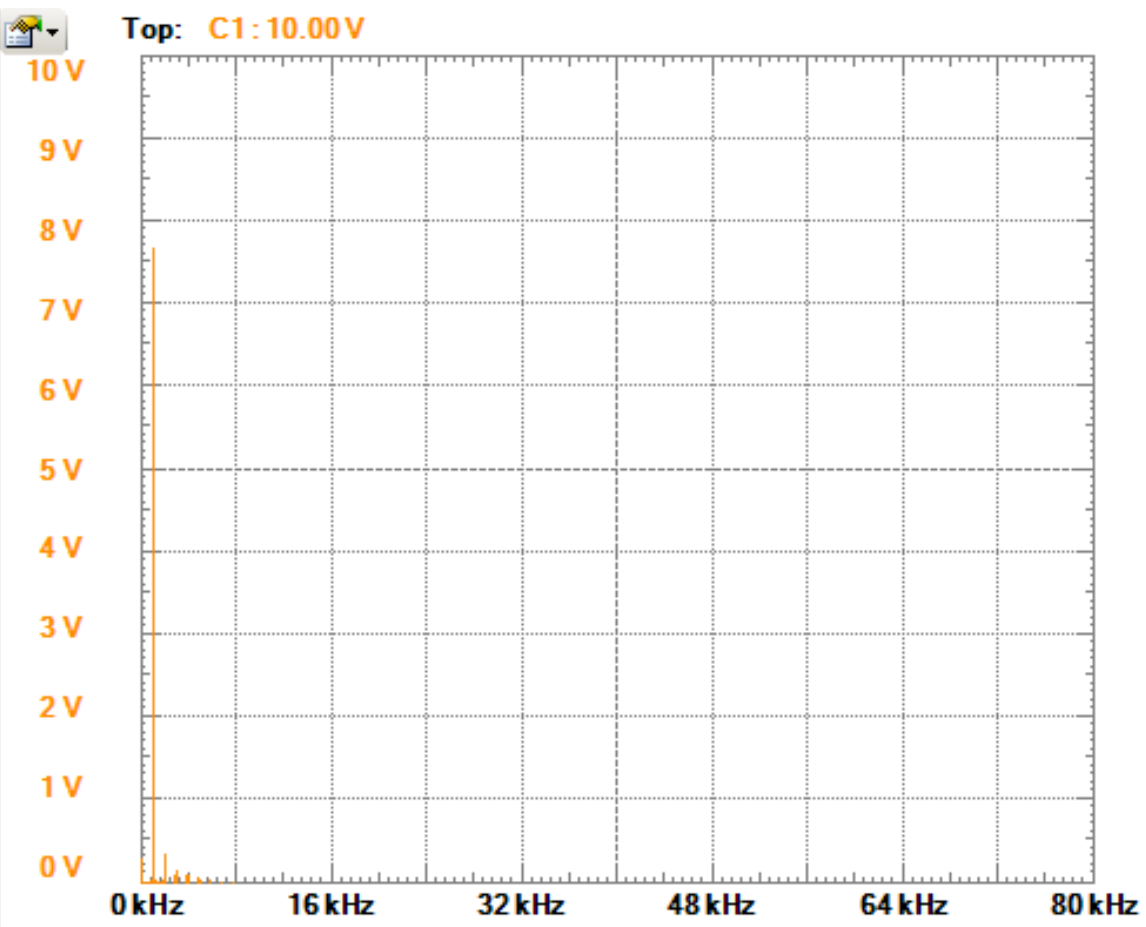

Figure 12: The spectrum of the output of the Wien bridge oscillator. The table shows the the values of the harmonics.

(8) Basic Comparator Circuits and Power Supply Monitor.

In this laboratory, students displayed the DC transfer curves of a 311 comparator in both basic and emitter-following configurations. A power supply monitor was built to illustrate the concept of a window detector using comparators. The schematic for the power supply monitor is shown in Figure 13. The heart of the circuit is a window detector formed by the two comparators and $R_{1}, R_{2}$ and $R_{3}$ used to sense when $V P+$ is within $\pm 5 \%$ of $8 V$. The zener diode $Z_{1}$ forms a reference for the window detector and $R_{5}$ biases $Z_{1}$. The output circuit consists of resistor $R_{4}$, $\mathrm{R}_{6}, \mathrm{LED}_{1}$ and $\mathrm{Q}_{1}$. The value of $\mathrm{R}_{4}$ determines the amount of base current supplied to $\mathrm{Q}_{1}$ when 
$\mathrm{Q}_{1}$ is on. The value of $\mathrm{R}_{6}$ sets the current level of $\mathrm{LED}_{1}$ when $\mathrm{LED}_{1}$ is on. $\mathrm{LED}_{1}$ is on when $\mathrm{VP}+$ is within $\pm 5 \%$ of $8 \mathrm{~V}$.

This was a design, simulate, build, test, and evaluate experiment.

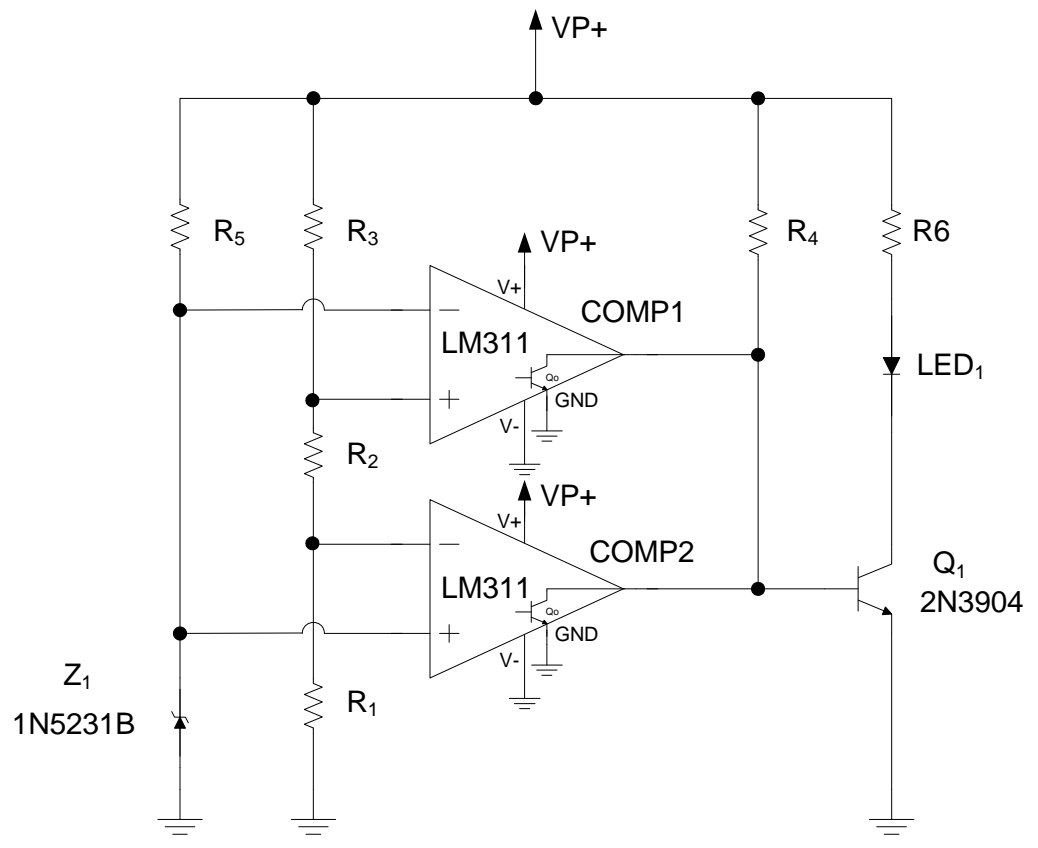

Figure 13: A power supply monitor. The heart the circuit is a window detector.

\section{Assessment}

Non-formal methods were used to assess the effectiveness of the laboratory exercises. This includes observations and a student survey.

Using the board did not seem to negatively impact student performance. On the whole, most of the students seemed to enjoy the course much more than in the past. It is hoped that in the future this will motivate students to perform better in the conceptual side of the class.

Even as seniors, students showed signs of a lack of basic laboratory skills at the beginning of the course. This included circuit construction so that the circuit could be easily debugged if necessary and building a circuit in "parts" and testing as each part was included. Debugging skills were lacking as well. By the end of the semester, skills in each of these three areas improved significantly in many cases.

A survey was completed by fourteen students. The results of the survey are presented in Table I. Generally, the results show that the students felt the laboratory reinforced the concepts discussed in class. Importantly, most students agreed or strongly agreed that the laboratory assignments 
added value to the class and be kept as part of the class. Development of formal assessment tools are planned for future courses.

\section{Present and Future work}

There are several activities being conducted in the Spring Semester of 2011 to determine if and where the board will be useful in the EE curriculum at the University of Idaho. The board is being used in a junior level electronics class. Experiments utilizing the board are being developed for a introductory freshman level electrical engineering course. It is also being used for a senior design project for an engineering outreach student.

Table I. Data from a classroom assessment. ${ }^{1}$ A total of 14 students participated in the survey.

\begin{tabular}{|l|c|}
\hline Question & $\begin{array}{c}\text { Avr. } \\
\text { Score }\end{array}$ \\
\hline The laboratory portion of the course using the Digilent board added value to the course. & 4.6 \\
\hline The laboratory assignments helped solidify basic fundamental concepts discussed in class. & 4.5 \\
\hline $\begin{array}{l}\text { The laboratory assignments helped solidify basic fundamental concepts discussed in class in } \\
\text { ways that traditional assignments do not. }\end{array}$ & 4.4 \\
\hline $\begin{array}{l}\text { The laboratory assignments helped solidify basic fundamental concepts discussed in class in } \\
\text { ways that simulations do not. }\end{array}$ & 4.2 \\
\hline The length of the laboratory assignments was appropriate. & 3.9 \\
\hline By the end of the course, I become stronger at building and testing electronic circuits. & 4.4 \\
\hline By the end of the course, my practical skills in electronics became stronger. & 4.4 \\
\hline By the end of the course, my practical knowledge in electronics became stronger. & 4.1 \\
\hline If I had to do it again, I would prefer the lab assignments in ECE 416 were kept. & 4.4 \\
\hline I found that the Digilent board was easy to use. & 4.4 \\
\hline I found that the Digilent board was more convenient to use than a regular laboratory. & 4.3 \\
\hline $\begin{array}{l}\text { I found my laboratory experience using the Digilent board to be as good as it would be in a } \\
\text { one of the EE department's laboratory. }\end{array}$ & 4.1 \\
\hline $\begin{array}{l}\text { I would have liked to have had the Digilent Board in ECE } 210 \text { (assuming it would be used in at } \\
\text { least ECE 210, 212, and 310). }\end{array}$ & 3.9 \\
\hline I would have purchased the Digilent Board at some point in my undergraduate had it been \\
\hline
\end{tabular}

${ }^{1}$ Scale $5=$ strongly agree, $4=$ agree, $3=$ neutral, $2=$ disagree, $1=$ strongly disagree. 


\section{Summary}

A description of an "Electronics Explorer Board" used in a senior level analog electronics course at the University of Idaho has been presented. A set of experiments using and the implementation and results have been discussed. The experiments are designed to be part of the homework assignment. The outcome of the course was positive. Not only did laboratory skills improve, but students generally felt that the basic concepts discussed in class were more meaningful. Moreover, they enjoyed it.

The key features of the board that make it useful in the classroom are convenience, ease of use, and powerful features. These features make it very easy to bring the laboratory experiments into the classroom when compared to having to be on-campus in a traditional laboratory setting. 


\section{References}

[1] John Dewey, "Experience and Education," 1997, Free Press Publications

[2 ] D.A. Kolb, Experiential Learning: Experience as the Source of Learning and Development. Englewood Cliffs, NJ, Prentice-Hall, 1984.

[ 3] B. McCarthy, The 4MAT System: Teaching to Learning Styles with Right/Left Mode Techniques. Barrington, IL, EXCEL, Inc., 1987.

[4] J.E. Stice, "Using Kolb's Learning Cycle to Improve Student Learning." Engr. Education, 77, 291-296 (1987).

[5] J.N. Harb, S.O. Durrant, and R.E. Terry. "Use of the Kolb Learning Cycle and the 4MAT System in Engineering Education." J. Engr. Education, 82(2), 70-77 (1993).

[6] R. A. Rohrer, "Taking circuits seriously," IEEE Circuits Devices Mag., vol. 6, no. 4, pp. 27-31, July 1990.

[7] Y. Tsividis, "Turning students on to circuits", IEEE CAS Magazine, Vol. 9. No 1, First Quarter 2009, pp. 58-63.

[8] Myers, C., and T.B. Jones (1993). Promoting Active Learning: Strategies for the College Classroom, San Francisco: Jossey-Bass.

[9] Clark, R.L. Flowers, G.H. Doolittle, P. Meehan, K. Hendricks, R.W., "Work in progress transitioning Lab-in-a-Box (LiaB) to the community college setting,"39th IEEE Frontiers in Education Conference,Oct. 2009, pp. 18-21 